\title{
The Association between Trichomonas Vaginalis Infection and The Risk of Benign Prostate Hyperplasia, Prostate Cancer, and Bladder Cancer in Patients: A Nationwide Population-Based Case-Control Study
}

\author{
Hung Yi Yang \\ Tri-Service General Hospital \\ Ruei-Yu Su \\ Tri-Service General Hospital \\ Chi-Hsiang Chung \\ National Defense Medical Center \\ Kuo-Yang Huang \\ National Defense Medical Center \\ Wu-Chien Chien \\ National Defense Medical Center \\ Hsin-Chung Lin ( $\square$ hsinchunglin@gmail.com ) \\ Tri-Service General Hospital \\ Hsin-An Lin \\ Tri-Service General Hospital Songshan Branch \\ Jui-Yang Wang \\ Tri-Service General Hospital Songshan Branch \\ Chien-Chou Chen \\ Tri-Service General Hospital Songshan Branch
}

\section{Research Article}

Keywords: Trichomonas vaginalis, benign prostate hyperplasia (BPH), prostate cancer (PCa), bladder cancer (BC)

Posted Date: November 11th, 2021

DOI: https://doi.org/10.21203/rs.3.rs-740634/v2

License: @ (i) This work is licensed under a Creative Commons Attribution 4.0 International License. Read Full License 


\section{Abstract}

Introduction: Trichomonas vaginalis infection is one of the most widespread sexually transmitted infections in the world. There are approximately 276 million cases worldwide. Most men remain undiagnosed and untreated because they are asymptomatic. The chronic inflammation induced by persistent infection may increase the risk of developing genitourinary cancers. In this study, we aimed to investigate the association between trichomoniasis and benign prostate hyperplasia (BPH), prostate cancer (PCa), and bladder cancer (BC) in Taiwan.

Material and method: We designed a case-control study by using the database of the National Health Insurance program in Taiwan. We used the International Classification of Diseases, 9th Revision classifications to classify all the medical conditions in the case and control groups. All odds ratios (ORs) and 95\% confidence intervals (Cls) were analyzed using multivariable logistic regression to adjust for all comorbidities and variables.

Result: From 2000 to 2015, we enrolled a total of 62,544 individuals as the case group and 187,632 as the control group. Trichomoniasis exposure had a significant association with $\mathrm{BPH}$ and $\mathrm{PCa}$ (adjusted $\mathrm{OR}$ : $\mathrm{BPH}=2.685,95 \% \mathrm{Cl}=1.233-4.286, P=0.013 ; \mathrm{PCa}=5.801,95 \% \mathrm{Cl}=1.296-26.035, P=0.016$ ). The relative risk was much higher if patients had both trichomoniasis and depression (adjusted $\mathrm{OR}=7.682,95 \% \mathrm{Cl}=5.730-9.451, P<0.001$ ).

Conclusion: Men with trichomoniasis had a significantly higher risk of developing BPH and PCa than those without. Healthcare professionals should not only pay more attention to disease treatment, but also to public health education.

\section{Introduction}

Benign prostate hyperplasia (BPH), prostate cancer (PCa), and bladder cancer (BC) are common diseases in the elderly male population. The pathological mechanism of these diseases is not yet fully understood. Inflammation of the prostate, which can cause proliferation of epithelium and stroma, is considered to be related to both BPH and PCa [1, 2]. In addition, urinary tract infection (UTI) is significantly associated with genitourinary cancers (GUC), including kidney, prostate, and bladder cancers [3]. Trichomonas vaginalis infection is one of the most common sexually transmitted infections (STIs), accounting for approximately 276.4 million new cases annually [4]. Because most male patients are asymptomatic and remain undiagnosed and untreated, persistent infection may cause chronic inflammation, which may increase the risk of GUC. There is a lack of research into the relationship between $T$. vaginalis infection and BC; however, some studies have mentioned that $T$. vaginalis infection may induce proliferation of prostatic epithelial cells and stromal cells [5, 6]. Some in vitro studies showed that PCa may be associated with the up-regulation of the expression of genes that can control cell apoptosis or be overexpressed as a proto-oncogene [7, 8]. The study from Vienna General Hospital discovered that 29/86 (33.7\%) patients with BPH were positive for T. vaginalis on polymerase chain reaction (PCR) testing [9]. The Health Professionals Follow-up Study (HPFS) demonstrated that $T$. vaginalis seropositivity had a positive correlation with PCa risk [10]. However, conflicting results have also been reported. Miguelle et al. demonstrated that there was no significant association between $T$. vaginalis infection and PCa in Caucasian or African-American groups [11]. Another multicenter study in the USA revealed that patients with a history of STIs and positive STI serologies demonstrated no association with $\mathrm{BPH}$ [12]. In addition, there is still a lack of related literature regarding BC and Asian male populations. Thus, this study aimed to examine the association between $T$. vaginalis infection and BPH, BC, or PCa.

\section{Material And Methods}

\section{Data source}

We designed a population-based nationwide nested case-control study and obtained inpatient and outpatient files from Taiwan's National Health Insurance Research Database (NHIRD). The data were collected from the Longitudinal Health Insurance Database 2005 (LHID2005), a part of NHIRD. We randomly selected approximately 2,000,000 people among the total population. All personal information was encrypted by National Health Research Institutes before released.

\section{Identification of the case and control groups}

We selected patients from 2000 to 2015 who had been diagnosed with BPH, PCa, or BC based on the International Classification of Diseases, 9th Revision, Clinical Modification (ICD-9-CM) codes as the case group (Table S1). We defined the date of the first disease diagnosis as the index date. We also used ICD-9CM codes to identify patients with $T$. vaginalis infection (Table S1). In contrast, the control groups were patients without BPH, PCa, or BC. Among all patients in the case and control groups, we not only selected patients in a 1:3 case:control ratio, matching based on age and index date, but also excluded (1) women and patients of unknown sex, (2) patient's aged less than 18 years, and (3) those last diagnosed with trichomoniasis within 1 year before the index date (Fig. 1). The comorbidities in our study included hypertension, myocardial infarction, congestive heart failure, cerebral or peripheral vascular disease, dementia, chronic obstructive pulmonary disease (COPD), type 2 diabetes, renal disease, and malignant disease except PCa and BC. We also evaluated depression as one of the comorbidities in our study because it may be associated with some cancers [13].

\section{Statistical analysis}

The statistical analyses were performed using SPSS version 22.0 (IBM Corp, Armonk, NY, USA). A P-value $<0.05$ was considered significant. The chi-squared or Fisher exact test was used to evaluate distributions between the case and control groups. Continuous variables were evaluated using the t-test. Unconditional multiple logistic regression analyses were performed to evaluate the risks of $\mathrm{BPH}, \mathrm{PCa}$, and $\mathrm{BC}$ associated with trichomoniasis after adjusting for age, insurance premium, comorbidities, season, urbanization, and level of care.

\section{Results}


Table 1 demonstrates the population distribution of different characteristics for 62,544 patients with BPH, PCa, or BC and 187,632 controls from 2000 to 2015 . There were no significant differences in age between groups after matching. The proportion with trichomoniasis in the case group was $0.02 \%$ (14/62,544), while it was $0.01 \%(14 / 187,632)$ in the control group $(P<0.001)$.

\section{Variable evaluation in the multiple logistic regression}

We present the results of the multivariable logistic regression analyses in Table 2. Patients with trichomoniasis had a significantly higher risk of BPH, PCa, or $\mathrm{BC}$ (adjusted odds ratio $[\mathrm{AOR}]=2.999,95 \%$ confidence interval $[\mathrm{Cl}]=1.426-5.301, \mathrm{p}=0.002$ ). There was also a significantly higher risk for patients with depression $(\mathrm{AOR}=3.124,95 \% \mathrm{Cl}=1.808-4.838, P<0.001)$. The opposite result was noted in patients with middle or high insurance premiums (insurance premium NT\$18,000-34,999: $\mathrm{AOR}=0.745,95 \% \mathrm{Cl}=0.688-0.799, P<0.001$; insurance premium $>\mathrm{NT} \$ 35,000: \mathrm{AOR}=0.836,95 \% \mathrm{Cl}=0.701-0.979, P=0.019)$. Patients diagnosed in summer, autumn, or winter also had significantly lower risk than the control group (summer: $\mathrm{AOR}=0.938,95 \% \mathrm{Cl}=0.902-0.953, P<$ 0.001; autumn: $\mathrm{AOR}=0.790,95 \% \mathrm{Cl}=0.758-0.805, P<0.001$; winter: $\mathrm{AOR}=0.862,95 \% \mathrm{Cl}=0.824-0.878, P<0.001)$. Patients who lived in areas with a higher urbanization level had a significantly higher risk of $\mathrm{BPH}, \mathrm{PCa}$, or $\mathrm{BC}$ (urbanization level 1: $\mathrm{AOR}=1.160,95 \% \mathrm{Cl}=1.124-1.189, P<0.001$; urbanization level 2: $A O R=1.211,95 \% \mathrm{Cl}=1.179-1.235, P<0.001)$ but had significantly lower risk when diagnosed at a higher level of care (hospital center: $A O R=0.819$, $95 \% \mathrm{Cl}=0.796-0.902, P<0.001$; regional hospital: $\mathrm{AOR}=0.745,95 \% \mathrm{Cl}=0.724-0.808, P<0.001)$ instead.

\section{Risk of $\mathrm{BPH} / \mathrm{PCa}$ and $\mathrm{BC}$ in the trichomoniasis group stratified by covariates}

The risk of $\mathrm{BPH}, \mathrm{PCa}$, or $\mathrm{BC}$ stratified based on variables using multivariable logistic regression is shown in Table 3. Patients with trichomoniasis had a 2.999 times higher risk of $\mathrm{BPH}, \mathrm{PCa}$, or $\mathrm{BC}$ than the control group $(\mathrm{AOR}=2.999,95 \% \mathrm{Cl}=1.426-5.301)$. In the case of trichomoniasis, there were significantly higher risks of $\mathrm{BPH}, \mathrm{PCa}$, or $\mathrm{BC}$ in patients aged $>65$ years old, with lower insurance premiums, with/without depression, first diagnosed in winter, urbanization level 2 , and first diagnosed in a local hospital (age > 65 years: $\mathrm{AOR}=3.685,95 \% \mathrm{Cl}=1.704-8.015$; insurance premium < NT\$18,000: $\mathrm{AOR}=2.999,95 \% \mathrm{Cl}=1.326-$ 5.301; with depression: $\mathrm{AOR}=3.104,95 \% \mathrm{Cl}=1.706-5.972$; without depression: $\mathrm{AOR}=2.545,95 \% \mathrm{Cl}=1.138-4.289$; first diagnosed in winter: $\mathrm{AOR}=4.806$, $95 \% \mathrm{Cl}=1.104-19.675$; urbanization level 2: $\mathrm{AOR}=3.284,95 \% \mathrm{Cl}=1.057-10.978$; first diagnosed in local hospital: $\mathrm{AOR}=15.121,95 \% \mathrm{Cl}=1.762-118.976$ ).

\section{Risk of BPH/PCa and BC in subgroup with $T$. vaginalis exposure and the joint effect}

Table 4 presents the $T$. vaginalis exposure ratio in each subgroup of $\mathrm{BPH} / \mathrm{PCa}$ and $\mathrm{BC}$. T. vaginalis exposure is significantly associated with a higher risk of $\mathrm{BPH}$ and $\mathrm{PCa}(\mathrm{BPH}: \mathrm{AOR}=2.685,95 \% \mathrm{Cl}=1.233-4.286, P=0.013$; $\mathrm{PCa}$ : $\mathrm{AOR}=5.801,95 \% \mathrm{Cl}=1.296-26.035, P=0.016)$, but has no significant association with $\mathrm{BC}(\mathrm{AOR}=4.012,95 \% \mathrm{Cl}=0.524-31.145, P=0.151)$. In addition, patients with both depression and $T$. vaginalis exposure had a significantly higher risk of developing $\mathrm{BPH}, \mathrm{PCa}$, or $\mathrm{BC}$ in comparison with other groups with only one condition or without them $(\mathrm{AOR}=7.682,95 \% \mathrm{Cl}=5.730-9.451, P<0.001)(\mathrm{Fig}$. 2).

\section{Discussion}

We designed this case-control study based on nationwide data from Taiwan NHIRD. We found that $T$. vaginalis infection was significantly associated with $\mathrm{BPH}$ and $\mathrm{PCa}$ in a male population. Therefore, T. vaginalis could be a pathogen that induces BPH and PCa. However, there was no significant association between trichomoniasis and BC. Furthermore, patients with both trichomoniasis and depression had 7.682 times higher risk of developing BPH, PCa, or BC. This result suggests that the joint effect of trichomoniasis and depression could increase the risk of BPH, PCa, or BC.

The mechanism of $T$. vaginalis inducing BPH and PCa still remains unclear. Several studies have demonstrated different possible mechanisms. In women, $T$. vaginalis induces pro-inflammatory cytokine production, including interleukin-6 (IL-6), interleukin-8 (IL-8), and chemokine ligand 2 (CCL2), while attaching to vaginal epithelial cells [14]. A similar inflammatory reaction was also noted in T. vaginalis-infected prostatic epithelial cells in some in vitro studies [5, 6]. Repeated cell damage and repair in chronic inflammation is likely to play an important role in inducing BPH [15]. Furthermore, the alteration in cytokine expression during chronic inflammation may have effects on cell growth and proliferation of the prostate epithelium and stroma in BPH ${ }^{15}$. The activated mast cells stimulated by T. vaginalis-infected prostatic epithelial cells can initiate IL-8 and CCL2 expression [5]. IL-8 could be a predictive marker for BPH [16]. Some in vitro studies demonstrated that IL-8 can stimulate fibroblast growth factor 2 (FGF-2), which causes the mitosis of prostate stromal cells [17]. IL-8 could also cause cyclin D1 expression to promote stromal cells proliferation [18]. In addition, CCL2, secreted by the prostatic stroma fibroblast, could promote both $\mathrm{BPH}$ and PCa progression [5].

T. vaginalis possibly induces carcinogenesis of the prostate. The infected prostatic epithelial cells produce IL-6 in chronic inflammation [19]. In early studies, an elevated serum IL-6 level was noted in patients with advanced PCa [20]. The positive correlation between IL-6 receptor expression and cell proliferation has been reported [21]. IL-6 also induces epithelial-mesenchymal transition (EMT) in breast cancer growth and metastasis [22], and the same reaction may also occur in prostatic epithelial cells [23]. In addition, more than one study has demonstrated that IL-6 could enhance androgen receptor (AR) activity and AR gene expression [24], which is also related to prostate cancer growth. Twu et al. demonstrated that $T$. vaginalis macrophage migration inhibitory factor (TVMIF) plays an important role in inducing PCa [7]. There are already studies that have proven that higher human macrophage migration inhibitory factor (HuMIF) levels are present in several cancers, including PCa [25]. The structure of TvMIF is similar to that of HuMIF, which might explain why TVMIF also has the ability to promote cell proliferation, sustain inflammation, and stimulate the growth of prostate cancer cells [7].

There were still a lack of studies to prove that trichomoniasis is associated with BC. We still included BC patients in our study because the inflammatory cytokinesfound in trichomoniasis, including IL-6 and IL-8, are also associated with a higher risk of developing BC [26, 27] and some parasites, such as 
Schistosoma haematobium, can induce BC. However, our study shows no significant association between T. vaginalis infection and BC probably because of limited sample.

Our results demonstrate that except for depression, no comorbidities had a significant association with BPH, PCa, or BC. The joint effect of trichomoniasis and depression increased the risk by 7.682 times that of the control group. A recent study showed that depression is associated with decreased immunity [28]. Moreover, depression can also cause cytokine dysregulation and increased serum IL-6 concentration [28], which might enhance carcinogenesis after T. vaginalis infection.

Although this study was a large-scale population-based nationwide design with long-term monitoring from 2000 to 2015 , there are still several limitations. First, the NHIRD does not contain detailed information regarding the histological and TNM classification of PCa and BC, serum sex hormone concentrations, family history, or personal history such as physical activity, alcohol consumption or tobacco smoking. Second, we did not include body mass index (BMI) as one of our variables. Obesity is one of the risk factors for BPH and PCa [29], which might affect their association with trichomoniasis. Third, our study might underestimate the exact number of patients with trichomoniasis. Most male patients would not seek treatment due to being asymptomatic, and ineffective screening protocols because of the lack of public health awareness could also lead to possible $T$. vaginalis infection being neglected [30]. Fourth, the number of cases of $\mathrm{BC}$ might be too small to be significant and the tracking time might not be sufficient for disease monitoring.

\section{Conclusion}

Male patients with $T$. vaginalis infection have an increased risk of developing BPH and PCa, especially in trichomoniasis patients with comorbid depression. Due to the lack of awareness of this pathogen, clinicians should not only treat patients who are already diagnosed but should also pay more attention to groups with higher trichomoniasis exposure risk.

\section{Abbreviations}

AOR: adjusted odds ratio; AR: androgen receptor; BC: bladder cancer; BMI: body mass index; BPH: benign prostate hyperplasia; CCL2: chemokine ligand 2; Cl: confidence interval; COPD: chronic obstructive pulmonary disease; EMT: epithelial-mesenchymal transition; FGF-2: fibroblast growth factor 2; GUC: genitourinary cancers; HPFS: Health Professionals Follow-up Study; HuMIF: human macrophage migration inhibitory factor; IL: interleukin; LHID2005: Longitudinal Health Insurance Database 2005; NHI: National Health Insurance; NHIRD: National Health Insurance Research Database; NT\$: New Taiwan Dollars; OR: odds ratio; PCa: prostate cancer; STI: sexually transmitted infection; T. vaginalis: Trichomonas vaginalis; TvMIF: Trichomonas vaginalis macrophage migration inhibitory factor; UTI: urinary tract infection

\section{Declarations}

\section{Acknowledgements}

We would like to thank the National Defense Medical Center team for support.

\section{Availability of data and materials}

Data supporting the conclusions of this article are included within the article and its additional files. The datasets used and/or analyzed during the present study will be made available by the corresponding author upon reasonable request.

\section{Authors' contributions}

$\mathrm{HCL}, \mathrm{HYY}$ and $\mathrm{CCC}$ conceived the idea and wrote the first draft manuscript. RYS and KYH contributed to the manuscript. WCC and CHC research data collection and statistical analyses. All authors read and approved the fnal manuscript.

\section{Funding}

This work was supported by Tri-Service General Hospital, Taiwan (TSGH-C108-003) to WCC and Tri-Service General Hospital SongShan Branch, Taiwan (TSGH-SS-D-110006) to CCC.

\section{Ethics approval:}

This study was approved by the Institutional Review Board of Tri-Service General Hospital, National Defense Medical Center, Taipei, Taiwan (TSGHIRB No. 2105-05-082).

\section{Consent for publication:}

Because the patient identifiers were encrypted before their data were used for research purposes to protect confidentiality, the requirement for written or verbal consent from patients for data linkage was waived.

Conflicts of Interest: The authors declare no competing interests.

\section{References}


1. St Sauver J.L. and S.J. Jacobsen, Inflammatory mechanisms associated with prostatic inflammation and lower urinary tract symptoms. Curr Prostate Rep, 2008;6:67-73.

2. Orsted, D.D. and S.E. Bojesen, The link between benign prostatic hyperplasia and prostate cancer. Nat Rev Urol, 2013;10:49-54.

3. Huang, C.H., Chou, Y.H., Yeh, H.W., et al., Risk of cancer after lower urinary tract infection: a population-based cohort study. Int J Environ Res Public Health, 2019;16:390.

4. World Health Organization (2012) Global incidence and prevalence of selected curable sexually transmitted infections - 2008 (WHO Geneva, Switzerland).

5. Kim, J.H., Kim, S.S., Han, I.H., et al., Proliferation of prostate stromal cell induced by benign prostatic hyperplasia epithelial cell stimulated with Trichomonas vaginalis via crosstalk with mast cell. Prostate, 2016;76:1431-44.

6. Kim, S.S., Kim, J.H., Han, I.H., et al., Inflammatory responses in a benign prostatic hyperplasia epithelial cell line (BPH-1) infected with Trichomonas vaginalis. Korean J Parasitol, 2016;54:123-32.

7. Twu, O., Dessi, D., Vu, A., et al., Trichomonas vaginalis Homolog of Macrophage Migration Inhibitory Factor Induces Prostate Cell Growth, Invasiveness, and Inflammatory Responses. Proc Natl Acad Sci U S A, 2014; 111:8179-84.

8. Sutcliffe, S., Neace, C., Magnuson, N.S., et al., Trichomonosis, a common curable STI, and prostate carcinogenesis--a proposed molecular mechanism. PLoS Pathog, 2012;8:e1002801.

9. Mitteregger, D., Aberle, S.W., Makristathis, A., et al., High detection rate of Trichomonas vaginalis in benign hyperplastic prostatic tissue. Med Microbiol Immunol, 2012;201:113-6.

10. Sutcliffe, S., Giovannucci, E., Alderete, J.F., et al., Plasma antibodies against Trichomonas vaginalis and subsequent risk of prostate cancer. Cancer Epidemiol Biomarkers Prev, 2006;15:939-45.

11. Marous, M., Huang, W.Y., Rabkin, C.S., et al., Trichomonas vaginalis infection and risk of prostate cancer: associations by disease aggressiveness and race/ethnicity in the PLCO trial. Cancer Causes Control, 2017;28:889-898.

12. Breyer, B.N., Huang, W.Y., Rabkin, C.S., et al., Sexually transmitted infections, benign prostatic hyperplasia and lower urinary tract symptom-related outcomes: results from the prostate, lung, colorectal and ovarian cancer screening trial. BJU Int, 2016;117:145-54.

13. Lin, C.L., Liu, T.C., Wang, Y.N., et al., The association between sleep disorders and the risk of colorectal cancer in patients: a population-based nested case-control study. In Vivo, 2019;33:573-579.

14. Han, I.H., Park, S.J., Ahn, M.H., et al., Involvement of mast cells in inflammation induced by Trichomonas vaginalis via crosstalk with vaginal epithelial cells. Parasite Immunol, 2012;34:8-14.

15. Schauer, I.G. and D.R. Rowley, The functional role of reactive stroma in benign prostatic hyperplasia. Differentiation, 2011;82:200-10.

16. Penna, G., Mondaini, N., Amuchastegui, S., et al., Seminal plasma cytokines and chemokines in prostate inflammation: interleukin 8 as a predictive biomarker in chronic prostatitis/chronic pelvic pain syndrome and benign prostatic hyperplasia. Eur Urol, 2007;51:524-33; discussion 533.

17. Giri, D. and M. Ittmann, Interleukin-8 is a paracrine inducer of fibroblast growth factor 2, a stromal and epithelial growth factor in benign prostatic hyperplasia. Am J Pathol, 2001;159:139-47.

18. MacManus, C.F., Pettigrew, J., Seaton, A., et al., Interleukin-8 signaling promotes translational regulation of cyclin D in androgen-independent prostate cancer cells. Mol Cancer Res, 2007;5:737-48.

19. Han, I.H., Kim, J.H., Kim, S.S., et al., Signalling pathways associated with IL-6 production and epithelial-mesenchymal transition induction in prostate epithelial cells stimulated with Trichomonas vaginalis. Parasite Immunol, 2016;38:678-687.

20. Adler, H.L., McCurdy, M.A., Kattan, M.W., et al., Elevated levels of circulating interleukin- 6 and transforming growth factor-beta1 in patients with metastatic prostatic carcinoma. J Urol, 1999;161:182-7.

21. Giri, D., M. Ozen, and M. Ittmann, Interleukin-6 is an autocrine growth factor in human prostate cancer. Am J Pathol, 2001;159:2159-65.

22. Sullivan, N.J., Sasser, A.K., Axel, A.E., et al., Interleukin-6 induces an epithelial-mesenchymal transition phenotype in human breast cancer cells. Oncogene, 2009;28:2940-7.

23. Rojas, A., Liu, G., Coleman, I., et al., IL-6 promotes prostate tumorigenesis and progression through autocrine cross-activation of IGF-IR. Oncogene, 2011;30:2345-55.

24. Lee, S.O., Lou, W., Hou, M., et al., Interleukin-6 promotes androgen-independent growth in LNCaP human prostate cancer cells. Clin Cancer Res, 2003;9:3706.

25. Hussain, F., Freissmuth, M., Völkel, D. et al., Human anti-macrophage migration inhibitory factor antibodies inhibit growth of human prostate cancer cells in vitro and in vivo. Mol Cancer Ther, 2013;12:1223-34.

26. Chen, M.F., Lin, P.Y., Wu, C.F., et al., IL-6 expression regulates tumorigenicity and correlates with prognosis in bladder cancer. PLoS One, $2013 ; 8: e 61901$.

27. Inoue, K., Slaton, J.W., Kim, S.J. et al., Interleukin 8 expression regulates tumorigenicity and metastasis in human bladder cancer. Cancer Res, 2000;60:2290-9.

28. Glaser, R., Robles, T.F., Sheridan, J., et al., Mild depressive symptoms are associated with amplified and prolonged inflammatory responses after influenza virus vaccination in older adults. Arch Gen Psychiatry, 2003;60:1009-14.

29. Allott, E.H., E.M. Masko, and S.J. Freedland, Obesity and prostate cancer: weighing the evidence. Eur Urol, 2013;63:800-9.

Roth, A.M., Williams J.A., Ly, R., et al., Changing sexually transmitted infection screening protocol will result in improved case finding for Trichomonas vaginalis among high-risk female populations. Sex Transm Dis, 2011;38:398-400. 
Table 1. Characteristics of the study group

\begin{tabular}{|c|c|c|c|c|c|c|c|}
\hline \multirow{2}{*}{$\begin{array}{l}\text { BPH/prostate cancer, bladder cancer } \\
\text { Variables }\end{array}$} & \multicolumn{2}{|l|}{ Total } & \multicolumn{2}{|l|}{ With } & \multicolumn{2}{|l|}{ Without } & \multirow[t]{2}{*}{$P$} \\
\hline & $\mathbf{n}$ & $\%$ & $\mathrm{n}$ & $\%$ & $\mathbf{n}$ & $\%$ & \\
\hline Total & 250,176 & & 62,544 & 25.00 & 187,632 & 75.00 & \\
\hline Trichomoniasis & & & & & & & 0.004 \\
\hline Without & 250,148 & 99.99 & 62,530 & 99.98 & 187,618 & 99.99 & \\
\hline With & 28 & 0.01 & 14 & 0.02 & 14 & 0.01 & \\
\hline Age (years) & \multicolumn{2}{|c|}{$73.15 \pm 11.41$} & \multicolumn{2}{|c|}{$73.21 \pm 10.65$} & \multicolumn{2}{|c|}{$73.13 \pm 11.65$} & 0.129 \\
\hline Age group (years) & & & & & & & 0.999 \\
\hline $18-44$ & 2,664 & 1.06 & 666 & 1.06 & 1,998 & 1.06 & \\
\hline $45-64$ & 50,292 & 20.10 & 12,573 & 20.10 & 37,719 & 20.10 & \\
\hline$\geq 65$ & 197,220 & 78.83 & 49,305 & 78.83 & 147,915 & 78.83 & \\
\hline Insurance premium (NT\$) & & & & & & & $<0.001$ \\
\hline$<18,000$ & 245,698 & 98.21 & 61,654 & 98.58 & 184,044 & 98.09 & \\
\hline $18,000-34,999$ & 3,654 & 1.46 & 712 & 1.14 & 2,942 & 1.57 & \\
\hline$\geq 35,000$ & 824 & 0.33 & 178 & 0.28 & 646 & 0.34 & \\
\hline Depression & & & & & & & $<0.001$ \\
\hline Without & 217,896 & 87.10 & 50,509 & 80.76 & 167,387 & 89.21 & \\
\hline With & 32,280 & 12.90 & 12,035 & 19.24 & 20,245 & 10.79 & \\
\hline CCl_R & $1.74 \pm 2.9$ & & $1.71 \pm 2$ & & $1.75 \pm 3$ & & $<0.001$ \\
\hline Season & & & & & & & $<0.001$ \\
\hline Spring (Mar-May) & 56,893 & 22.74 & 15,495 & 24.77 & 41,398 & 22.06 & \\
\hline Summer (Jun-Aug) & 60,567 & 24.21 & 15,709 & 25.12 & 44,858 & 23.91 & \\
\hline Autumn (Sep-Nov) & 72,621 & 29.03 & 16,666 & 26.65 & 55,955 & 29.82 & \\
\hline Winter (Dec-Feb) & 60,095 & 24.02 & 14,674 & 23.46 & 45,421 & 24.21 & \\
\hline Location & & & & & & & $<0.001$ \\
\hline Northern Taiwan & 99,711 & 39.86 & 26,475 & 42.33 & 73,236 & 39.03 & \\
\hline Central Taiwan & 71,555 & 28.60 & 16,878 & 26.99 & 54,677 & 29.14 & \\
\hline Southern Taiwan & 63,601 & 25.42 & 14,985 & 23.96 & 48,616 & 25.91 & \\
\hline Eastern Taiwan & 14,366 & 5.74 & 3,957 & 6.33 & 10,409 & 5.55 & \\
\hline Outlying islands & 943 & 0.38 & 249 & 0.40 & 694 & 0.37 & \\
\hline Urbanization level & & & & & & & $<0.001$ \\
\hline 1 (Highest) & 75,256 & 30.08 & 18,936 & 30.28 & 56,320 & 30.02 & \\
\hline 2 & 113,122 & 45.22 & 29,293 & 46.84 & 83,829 & 44.68 & \\
\hline 3 & 17,865 & 7.14 & 4,119 & 6.59 & 13,746 & 7.33 & \\
\hline 4 (Lowest) & 43,933 & 17.56 & 10,196 & 16.30 & 33,737 & 17.98 & \\
\hline Level of care & & & & & & & $<0.001$ \\
\hline Hospital center & 89,122 & 35.62 & 23,060 & 36.87 & 66,062 & 35.21 & \\
\hline Regional hospital & 115,596 & 46.21 & 26,602 & 42.53 & 88,994 & 47.43 & \\
\hline Local hospital & 45,458 & 18.17 & 12,882 & 20.60 & 32,576 & 17.36 & \\
\hline
\end{tabular}

$P:$ Chi-square/Fisher exact test on categorical variables and t-test on continue variables 
Table 2. Risk of BPH/prostate cancer and bladder cancer based on stated variables analyzed using multivariable logistic regression

\begin{tabular}{|c|c|c|c|c|c|c|c|c|}
\hline Variables & Crude OR & $95 \% \mathrm{Cl}$ & $95 \% \mathrm{Cl}$ & $P$ & Adjusted OR & $95 \% \mathrm{Cl}$ & $95 \% \mathrm{Cl}$ & $P$ \\
\hline \multicolumn{9}{|c|}{ Trichomoniasis } \\
\hline Without & Reference & & & & Reference & & & \\
\hline With & 3.000 & 1.430 & 6.294 & 0.004 & 2.999 & 1.426 & 5.301 & 0.002 \\
\hline \multicolumn{9}{|c|}{ Age group (years) } \\
\hline $18-44$ & Reference & & & & Reference & & & \\
\hline $45-64$ & 1.000 & 0.914 & 1.094 & 0.999 & 1.015 & 0.923 & 1.107 & 0.782 \\
\hline$\geq 65$ & 1.000 & 0.915 & 1.092 & 0.999 & 1.006 & 0.919 & 1.098 & 0.794 \\
\hline
\end{tabular}

Insured premium (NT\$)

$<18,000$

Reference

Reference

$18,000-34,999$

0.722

0.665

$0.784<0.001$

0.745

0.688

$0.799<0.001$

$\geq 35,000$

0.823

0.697

$0.971 \quad 0.021$

0.836

0.701

0.979

0.019

\section{Depression}

Without

Reference

With

CCI_R

3.286

0.996

$\begin{array}{lll}1.846 & 4.959 & <0.001 \\ 0.993 & 0.999 & 0.006\end{array}$

Reference

Season

Spring

Reference

Summer

0.936

0.912

0.796

0.776

0.863

0.841

Reference

Northern Taiwan

0.854

0.835

0.853

0.833

0.873

$<0.001$

3.124

1.000

1.808
0.998

4.838

$1.005 \quad 0.058$

Southern Taiwan

1.052

$0.873<0.001$

Reference

Eastern Taiwan

Outlying islands

0.992

1.011

1.094

0.012

$1.148 \quad 0.919$

0.938

0.902

0.953

$<0.001$

Urbanization level

1 (Highest)

2

3

1.113

$1.082<0.001$

0.790

0.862

0.758

0.805

$<0.001$

Had multicollinearity with urbanization level

Had multicollinearity with urbanization level

Had multicollinearity with urbanization level

Had multicollinearity with urbanization level

Had multicollinearity with urbanization level

Had multicollinearity with urbanization level

1.156

1.127

1.186

$<0.001$

1.160

0.951

1.033

0.685

1.211

0.987

Reference

4 (Lowest)

Reference

\section{Level of care}

Hospital center

0.883

0.861

0.905

$<0.001$

0.819

0.796

0.902

$<0.001$

Regional hospital

0.756

0.738

0.775

$<0.001$

0.745

0.724

0.808

$<0.001$

Local hospital

Reference

Reference

$P:$ Chi-square/Fisher exact test on categorical variables and t-test on continue variables; $\mathrm{OR}=$ odds ratio, $\mathrm{Cl}=$ confidence interval, $\mathrm{Adjusted} \mathrm{OR}$ : adjusted for variables listed in the table 
Table 3. Risk of BPH/prostate cancer and bladder cancer stratified by variables listed in the table by using multivariable logistic regression

\section{BPH / prostate, bladder cancer Stratified}

Total

Age group (years)

18-44

$45-64$

$\geq 65$

Insurance premium

(NT\$)

$<18,000$

With

Trichomoniasis Population \% exposure

14

62,544

0.022

Without

With vs. Without (Reference)

$18,000-34,999$

$\geq 35,000$

\section{Depression}

Without

With

10

10

14

0

0

0

14

\begin{tabular}{lll}
666 & 0.000 & 0 \\
\hline 12,573 & 0.000 & 2 \\
\hline 49,305 & 0.028 & 12
\end{tabular}

2

\begin{tabular}{lll}
\hline 61,654 & 0.023 & 14 \\
\hline 712 & 0.000 & 0 \\
178 & 0.000 & 0
\end{tabular}

50,509

0.0087

12,035

0.0837

\begin{tabular}{lll}
\hline 15,495 & 0.019 & 1 \\
\hline 15,709 & 0.013 & 4 \\
16,666 & 0.024 & 6 \\
\hline 14,674 & 0.034 & 3
\end{tabular}

\begin{tabular}{lll}
18,936 & 0.011 & 2 \\
\hline 29,293 & 0.020 & 6 \\
\hline 4,119 & 0.024 & 1 \\
10,196 & 0.049 & 5
\end{tabular}

2
6
1
5

\section{Level of care}

Hospital center

Regional hospital

Local hospital

$\begin{array}{llll}1 & 23,060 & 0.004 & 3 \\ 7 & 26,602 & 0.026 & 10 \\ 6 & 12,882 & 0.047 & 1\end{array}$

$\begin{array}{llll}1 & 23,060 & 0.004 & 3 \\ 7 & 26,602 & 0.026 & 10 \\ 6 & 12,882 & 0.047 & 1\end{array}$

6

$P:$ Chi-square/Fisher exact test on categorical variables and t-test on continue variables; Adjusted OR = Adjusted odds ratio: adjusted for the variables listed in Table 2; $\mathrm{Cl}=$ confidence interval 
Table 4. BPH/prostate cancer and bladder cancer subgroups analyzed using multivariable logistic regression

\begin{tabular}{|c|c|c|c|c|c|c|c|c|c|c|c|c|}
\hline $\begin{array}{l}\text { BPH/prostate } \\
\text { cancer, } \\
\text { bladder } \\
\text { cancer } \\
\text { subgroup }\end{array}$ & $\begin{array}{l}\text { Trichomoniasis } \\
\text { exposure }\end{array}$ & Population & $\%$ & $\begin{array}{l}\text { Adjusted } \\
\text { OR }\end{array}$ & $95 \% \mathrm{Cl}$ & $95 \% \mathrm{Cl}$ & $P$ & $\begin{array}{l}\text { Adjusted } \\
\text { OR }\end{array}$ & $95 \% \mathrm{Cl}$ & $95 \% \mathrm{Cl}$ & $P$ & $\begin{array}{l}\text { Adjusted } \\
\text { OR }\end{array}$ \\
\hline Without & 14 & 187,632 & 0.007 & Reference & & & & Reference & & & & Reference \\
\hline With & 14 & 62,544 & 0.022 & 2.999 & 1.426 & 5.301 & 0.002 & & & & & \\
\hline $\begin{array}{l}\text { BPH/prostate } \\
\text { cancer }\end{array}$ & 13 & 59,325 & 0.022 & & & & & 2.995 & 1.422 & 4.389 & 0.003 & \\
\hline $\mathrm{BPH}$ & 11 & 51,482 & 0.021 & & & & & & & & & 2.685 \\
\hline $\begin{array}{l}\text { Prostate } \\
\text { cancer }\end{array}$ & 2 & 6,254 & 0.032 & & & & & & & & & 5.801 \\
\hline $\begin{array}{l}\text { Bladder } \\
\text { cancer }\end{array}$ & 1 & 3,873 & 0.026 & & & & & 4.012 & 0.524 & 31.145 & 0.151 & 4.012 \\
\hline
\end{tabular}

$P:$ Chi-square/Fisher exact test on categorical variables and t-test on continue variables; Adjusted OR $=$ adjusted odds ratio (adjusted for the variables listed it interval

Table 5. Risk of BPH/prostate cancer or bladder cancer stratified by trichomoniasis and depression status using logistic regression

\begin{tabular}{llllll} 
Trichomoniasis & Depression & Adjusted OR & $95 \% \mathrm{Cl}$ & $95 \% \mathrm{Cl}$ & $\boldsymbol{P}$ \\
\hline Without & Without & Reference & & & \\
\hline With & Without & 2.975 & 1.429 & 3.608 & $<0.001$ \\
Without & With & 3.014 & 1.586 & 4.297 & $<0.001$ \\
\hline With & With & 7.682 & 5.730 & 9.451 & $<0.001$
\end{tabular}

$P$ : Chi-square/Fisher exact test on categorical variables and t-test on continue variables; Adjusted OR = adjusted odds ratio (adjusted for variables listed in Table 2); $\mathrm{Cl}=$ confidence interval

\section{Figures}


Outpatient and inpatient of Longitudinal Health Insurance Database in 2000-2015 in Taiwan

$36,464,228$ events; $1,936,512$ individuals

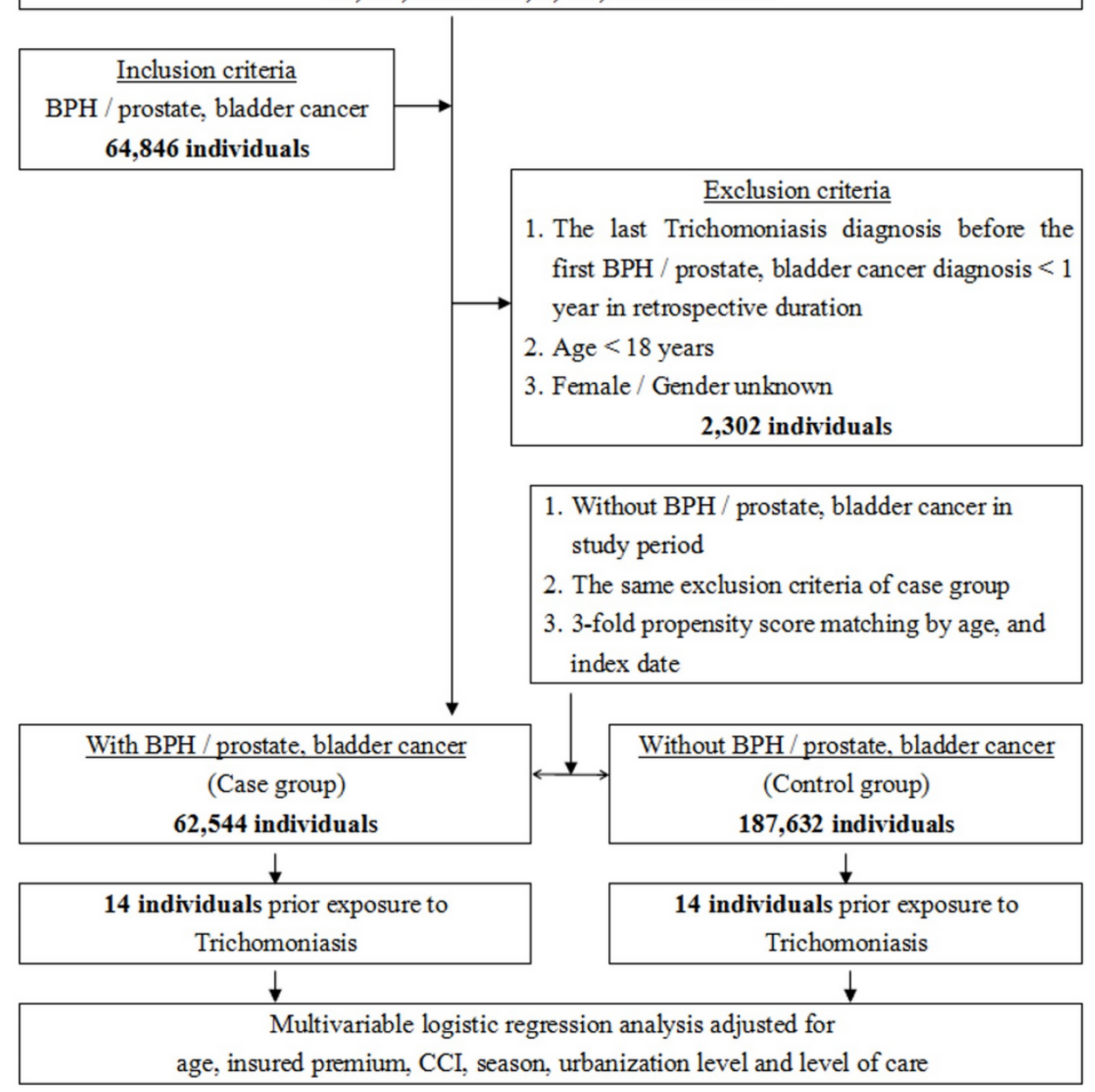

\section{Figure 1}

The flowchart of the study design (nested case-control study) from National Health Insurance Research Database in Taiwan. 


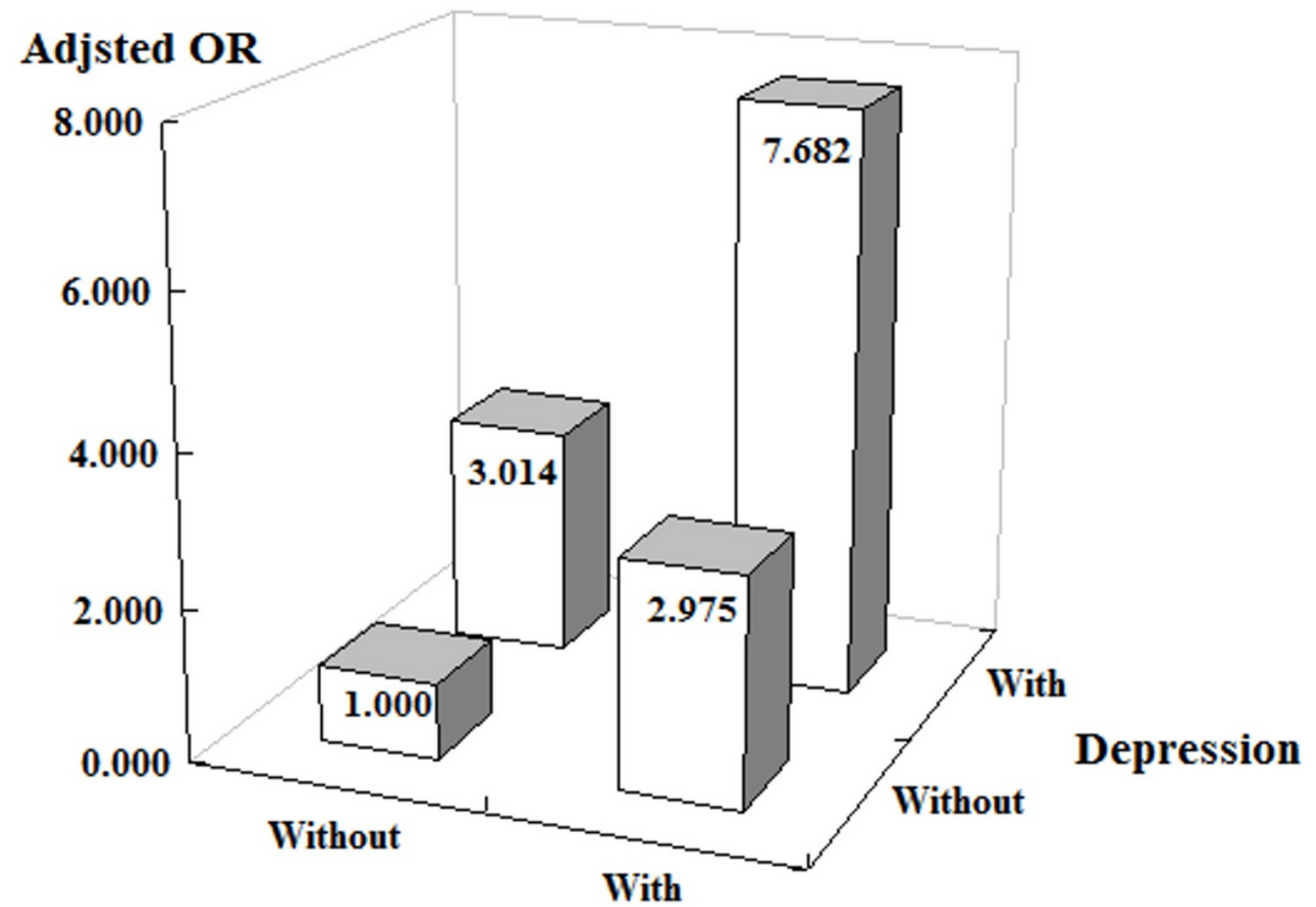

\section{Trichomoniasis}

Figure 2

Risk of $\mathrm{BPH} /$ prostate or bladder cancer stratified by trichomoniasis and depression status using logistic regression

\section{Supplementary Files}

This is a list of supplementary files associated with this preprint. Click to download.

- Tables1..docx 